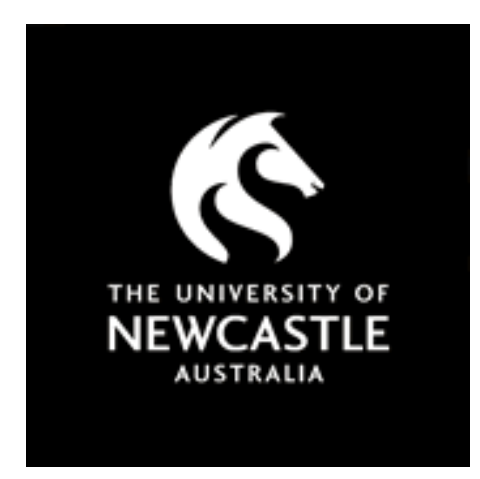

NOVA

University of Newcastle Research Online

nova.newcastle.edu.au

van Netten, K.; Ernst, T.; Moreno-Atanasio, R.; Galvin, K. P. "Selective agglomeration of fine coal using a water-in-oil emulsion", Published in Chemical

Engineering Research and Design Vol. 110, Issue June 2016, p. 54-61. (2016)

Available from: http://dx.doi.org/10.1016/j.cherd.2016.02.029

Accessed from: $\underline{\text { http://hdl.handle.net/1959.13/1323001 }}$

(C) 2016. This manuscript version is made available under the CC-BY-NC-ND 4.0 license http:// creativecommons.org/licenses/by-nc-nd/4.0/ 


\title{
SELECTIVE AGGLOMERATION OF FINE COAL USING A WATER-IN-OIL EMULSION
}

\author{
Kim van Netten*, Roberto Moreno-Atanasio \& Kevin P. Galvin \\ Centre for Advanced Particle Processing and Transport, Newcastle Institute for Energy and Resources, \\ University of Newcastle, Callaghan, NSW 2308, Australia \\ *kim.vannetten@newcastle.edu.au
}

\begin{abstract}
Fine coal may be separated from an aqueous suspension of coal and mineral particles through the application of a pure oil. The pure oil preferentially wets and agglomerates only the coal, forming a high quality, granular product. However, the use of the pure oil also comes at a relatively high cost and this cost prohibits commercial implementation of this process. In this work a new, economic binder, was introduced. This binder consisted of a high internal phase water-in-oil emulsion which was 95 vol\% water and 5 vol\% organic. This type of binder was selected as it possessed the hydrophobic surface functionality of oil while the space filling functionality of the binder was primarily satisfied by the dispersed water droplets within the emulsion. The application of this emulsion in the agglomeration process led to a 10-fold reduction in the organic liquid dosage required to achieve agglomeration as compared a pure oil binder. It was also observed that the agglomeration time required when using the emulsion binder was one order of magnitude less than required when using a pure oil binder. This variation was considered to result from the five orders of magnitude difference in the viscosity of the two binders.
\end{abstract}

\section{KEYWORDS}

Selective agglomeration, water-in-oil emulsion, fine coal

\section{INTRODUCTION}

Coal must be processed to separate it from the clays and other minerals with which it is mined. These minerals must be removed as they lower the quality, or grade, of the coal products. Coarse particles, $>200 \mu \mathrm{m}$, can be processed using water-based gravity separation techniques which rely on the large density disparity of the materials to be separated (Galvin and Iveson, 2013; Honaker et al., 2013). Fine particles, on the other hand, cannot be effectively processed using these techniques (Honaker et al., 2013). That is, a separation cannot be achieved on a reasonable time scale due to the small size of the particles and the resulting limited effect of gravity. Therefore, other techniques which discriminate between the different particle types based on their surface chemistry are employed. The most prominent of these techniques is flotation. In flotation a separation is achieved by contacting the aqueous slurry of fine particles with fine air bubbles. The hydrophobic coal particles attach to the bubbles and rise to the surface for collection whereas the hydrophilic mineral particles remain finely dispersed in suspension. Flotation has been applied with great success; however difficulties can be encountered when the coal to be processed contains a large amount of ultra-fine material or there is a substantial level of clays (Mehrotra et al., 1983; Miettinen et al., 2010). In a commercial setting, these difficult fine coal feeds are generally classified as waste as their processing is not economically viable. Therefore, a fine coal processing technique is required that is both effective on all fine coal feeds and economically viable.

Selective agglomeration is a technique which has received considerable attention in the past as having the potential to solve the aforementioned problems in fine coal processing (Brisse and 
McMorris, 1959; Mehrotra et al., 1983, Shrauti and Arnold, 1994, Swanson et al., 1977). As similar to flotation, the separation method applied in selective agglomeration is based on the differing surface chemistry of the materials. However, instead of air bubbles, a hydrophobic liquid binder is used to achieve the separation. Under the application of agitation this binder, usually pure oil, preferentially wets and agglomerates only the hydrophobic coal particles (Steedman and Krishnan, 1987). These product agglomerates can then be separated from the still finely dispersed hydrophilic clay particles using a screen separation (Steedman and Krishnan, 1987). Almost complete recovery of the carbonaceous material can be achieved using this method and the product is usually of high quality, i.e. has a low mineral matter content (Aktas, 2002; Swanson et al., 1977). There is also no lower limit on the size of particle that can be processed and the separation is not hindered by the presence of clays (Capes and Germain, 1982; Mehrotra et al., 1983). It was for these reasons that a considerable effort was made to develop a commercial fine coal agglomeration process. However these attempts were unsuccessful due to unfavourable economics (Bensley et al., 1977; Capes and Darcovich, 1984; Shrauti and Arnold, 1994).

The main factor which influences the economic viability of a fine coal agglomeration process is the cost of the pure oil binder. For a successful agglomeration process a dosage of $10-20 \mathrm{wt} \%$ is required (Garcia et al., 1995; Mehrotra et al., 1983; Swanson et al., 1977). The exact dosage is, of course, dependent upon the characteristics of the coal feed but in any case there must be sufficient binder volume available to fill the void spaces within the agglomerates and, to a certain extent, provide surface coverage of the hydrophobic particles. This saturated state, known as the capillary state, must be achieved as it results in a maximum in agglomerate strength and sphericity (Capes and Germain, 1982). At dosages below $10-20 \mathrm{wt} \%$ the structural integrity of the agglomerates is low and as such they become difficult to recover using a screen or other gravity separation technique. However, many authors have noted that for fine coal agglomeration to be a commercial success, the level, and thus cost, of the oil must be significantly reduced (Darcovich et al., 1988; Mehrotra et al., 1983; Shrauti and Arnold, 1994). Therefore, a new binder was investigated in this work in an attempt to reduce the amount of oil required and develop an economically viable agglomeration process.

The binder used in this work was a high internal phase water-in-oil emulsion. A high internal phase (HIP) emulsion is an emulsion in which the volume fraction of the dispersed phase is greater than 0.74; the maximum theoretical packing fraction of close packed spheres (Cameron, 2005). Figure 1 presents a comparison between the proposed emulsion binder and a traditional pure oil binder and illustrates the potential of the emulsion to reduce the amount, and thus cost, of the oil required in the process.

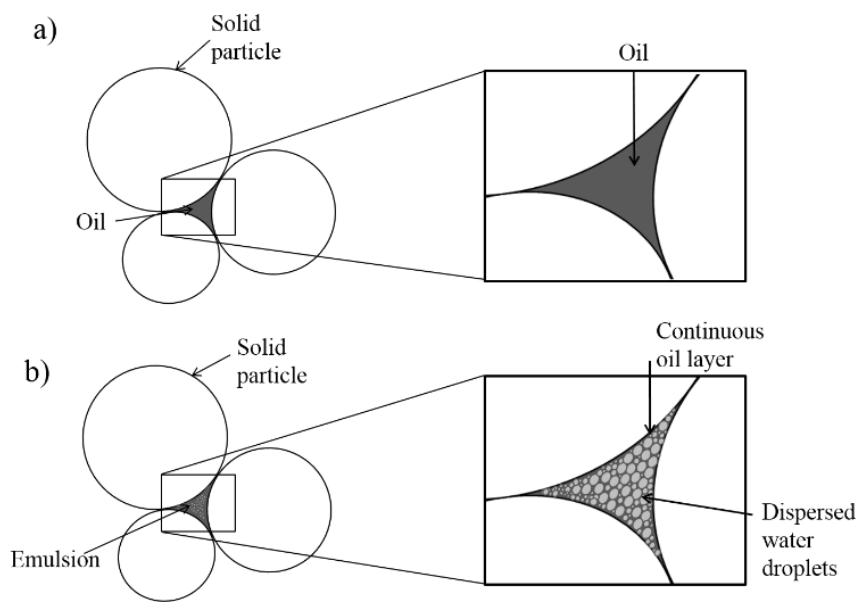

Figure 1. Three particles agglomerated using a) pure oil and b) a high internal phase water-in-oil emulsion 
Figure 1 shows two groups of three particles agglomerated using a liquid binder. In Figure 1a, the binder used is a pure oil, such as diesel, and in Figure $1 \mathrm{~b}$ the binder used is the emulsion. It can be seen in the figure that both binders have the capability to selectively agglomerate hydrophobic coal particles. That is, the oil is inherently hydrophobic and the emulsion is hydrophobic as oil forms the continuous phase. Also, both binders can fill the void space within the agglomerate, thus satisfying the requirement for the creation of strong and discrete agglomerates. Now, when an oil binder is used, as in Figure 1a, the oil can be seen to completely fill the void space. However when the emulsion is used, as in Figure 1b, the void space is filled only to a small extent by the oil as the dispersed water droplets occupy the majority of the space. Indeed, it is this space-filling functionality of the water droplets which creates the potential to greatly reduce the amount of oil required to form agglomerates.

Initially it was considered that the reduction in the oil requirement could be quantified if the composition of the emulsion was known. For example, it was thought that if an emulsion with a dispersed phase volume fraction of 0.90 was used, a 10 -fold reduction would be achieved as only one-tenth of the void space would be occupied by oil. However, this calculation assumed that the emulsion agglomerated fine particles in the exact same manner as pure oil and previous work has indicated that this is not the case (van Netten et al., 2014; 2015). The emulsion appeared to act markedly different to a pure oil and its application added new dimensions to the process of agglomeration. For example, it was observed that the emulsion could agglomerate coal much faster than pure diesel (van Netten et al., 2015). Also, the stability of the highly concentrated emulsion was shown to be an issue in the turbulent, aqueous environment of the agglomeration process. That is, it appeared as though the emulsion was breaking down or degrading during the agglomeration process. Emulsion degradation is highly undesirable as it negates the benefits gained through the creation of the emulsion structure and, therefore, diminishes the potential of the emulsion to reduce the oil requirement.

In previous work, the effects of the aqueous phase composition, the emulsifier type and the aqueous phase volume fractions on the performance of the emulsion as a binder were investigated (van Netten et al., 2014). The performance of the emulsion refers to the reduction in the organic liquid dosage required to achieve agglomeration as compared to a pure oil binder for the same feed. Initially only a 3-fold reduction in the organic liquid dosage was achieved through the application of the emulsion (van Netten et al., 2014). However, it was found that the presence of salt within the dispersed aqueous phase improved the performance, i.e. led to a further reduction in the organic liquid dosage. It was considered that this result was achieved because the presence of the salt improved the stability of the emulsion such that it degraded to a lesser extent. It was also found that the emulsions with the higher dispersed volume fractions had the best performance, i.e. achieved the greatest reductions in the organic liquid dosage (van Netten et al., 2014). This result was important as it qualitatively confirmed that the reduction in the organic liquid dosage related to the extent that water replaced oil within the void space of the agglomerate. Finally, emulsions made with sorbitan monooleate (SMO) as the emulsifier performed better than emulsions made with a polyisobutylene (PIB) type emulsifier (van Netten et al., 2014). This was a surprising result as SMO generally produces less stable HIP water-in-oil emulsions than PIB. Therefore, it appeared that use of SMO enhanced another aspect of the emulsion such that it was more suitable for use as a binder in the agglomeration process. Overall, the best result achieved in the previous work was a 7.5-fold reduction and this was achieved using an emulsion with the following composition: 5 vol\% SMO, 5 vol\% diesel and 90 vol\% aqueous $\mathrm{NaCl}$ solution (van Netten et al., 2014). Furthermore, taken as a whole, the previous work indicated that the performance of the emulsion could be improved by improving the stability of the emulsion and by modifying the properties of the emulsion such that it was more suitable for use in this new application.

This study extends the previous work by exploring the performance of a newly formulated emulsion. The formulation tested in this study was $2.5 \mathrm{vol} \%$ kerosene, $2.5 \mathrm{vol} \% \mathrm{SMO}$ and $95 \mathrm{vol} \%$ 
aqueous $\mathrm{NaCl}$ solution and was developed as a result of the findings in the previous work. Once again, the aim of this work was to produce a binder which could agglomerate coal with the least amount of organic liquid. The performance of the newly formulated emulsion was tested against two pure oil binders. An investigation into the kinetics of agglomerate growth for a pure kerosene binder and the emulsion was also carried out to elucidate the apparent variation in the agglomeration kinetics. Finally, as degradation of the emulsion has been raised as an issue in previous work a study into the stability of the emulsion in the turbulent, aqueous environment was also carried out.

\section{EXPERIMENTAL METHOD}

\subsection{Materials}

Kerosene was sourced from Recochem Inc and was used without any chemical or physical modifications. The density and viscosity of kerosene are $810 \mathrm{~kg} / \mathrm{m}^{3}$ and $0.0016 \mathrm{~Pa}$ s, respectively (Recochem, 2011). Diesel was sourced from a local fuel distribution centre and was used without any chemical or physical modifications. The density and viscosity of diesel are $830 \mathrm{~kg} / \mathrm{m}^{3}$ and $0.0025 \mathrm{~Pa}$ s, respectively (ExxonMobil, 2009). Sorbitan mono-oleate (SMO) was sourced from Sigma-Aldrich and was also used without any physical or chemical modifications. The density and viscosity of SMO are $990 \mathrm{~kg} / \mathrm{m}^{3}$ and $1-2 \mathrm{~Pa} \mathrm{~s}$, respectively (Sigma-Aldrich, 2013). Sodium chloride salt was sourced from Cerebos Ltd and dissolved in tap water at a concentration of $3 \mathrm{wt} \%$. The resulting aqueous salt solution was used to form the aqueous phase of the emulsion. Tap water was also used as the suspending liquid in all agglomeration experiments.

The coal used in all experiments was an Australian bituminous coal sourced from the Upper Hunter Valley. The feed was received, stored and sub-sampled immersed in water to hinder surface oxidation of the particles. Presented in Figure 2 is the size distribution of the coal feed. As can be seen the feed contained a large proportion of ultra-fine, $<100 \mu \mathrm{m}$, material.

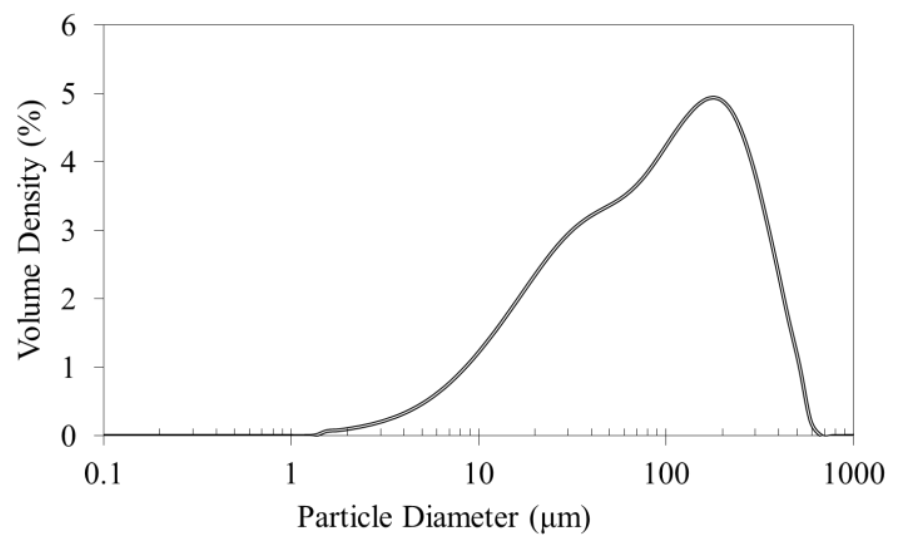

Figure 2. Size distribution of the feed used in all experiments.

The ash $\%$ of the coal feed was low at $10 \%$. A low ash coal was selected for use in this study as the focus was on the ability of the emulsion to agglomerate coal and the mechanisms by which this is achieved. Of course, the ability of the emulsion to agglomerate coal in a selective manner, i.e. reject the mineral matter, is vital but not the focus of the work described in the present paper. Nevertheless, the selective functionality of the emulsion has been investigated and confirmed and this work will be published separately.

\subsection{Preparation of the High Internal Phase Emulsion}


The emulsion was prepared in a $300 \mathrm{~g}$ batch with a composition of $2.5 \mathrm{vol} \%$ kerosene, $2.5 \mathrm{vol} \%$ $\mathrm{SMO}$ and 95 vol\% aqueous $\mathrm{NaCl}$ solution. Initially, the organic components, the $\mathrm{SMO}$ and the kerosene, were placed in a stainless steel mixing bowl and combined using a Russell Hobbs handheld mixer $(350 \mathrm{~W})$. Under continued agitation at maximum speed, the aqueous salt solution was gradually added to the organic mixture. Care had to be taken when adding the aqueous salt solution to the organic mixture to avoid phase inversion of the emulsion. The mixture begins as a translucent orange liquid and gradually becomes a white, opaque, and firm gel-like substance due to the incorporation of the aqueous salt solution. Figure 3 presents the emulsion used in all of the agglomeration experiments. It should be noted that only $5 \%$ of the volume of the emulsion is organic liquid yet it is a hydrophobic material.

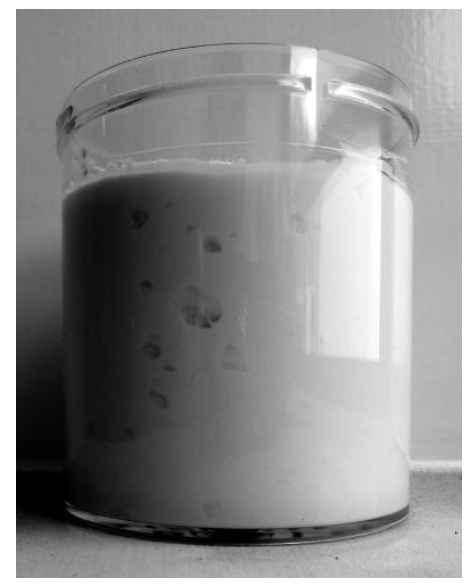

Figure 3. Emulsion binder. Composition: 2.5 vol\% kerosene, 2.5 vol\% sorbitan mono-oleate and 95 vol\% aqueous $\mathrm{NaCl}$ solution.

\subsection{Selective Agglomeration}

Selective agglomeration experiments were carried out to examine the influence of the organic liquid dosage on the product yield. In these experiments, $500 \mathrm{ml}$ of a $12 \mathrm{wt} \%$ coal slurry was transferred into a glass mixing vessel. This vessel was then placed on a Waring variable speed blender and the coal slurry was dispersed at $22000 \mathrm{rpm}$ for $1 \mathrm{~min}$. The binder, either the emulsion, pure kerosene or pure diesel, was then added in a single dose and mixing was continued for $120 \mathrm{~s}$ for the pure oils and $7 \mathrm{~s}$ for the emulsion. The agglomerated suspension was then poured over a $355 \mu \mathrm{m}$ screen. The product agglomerates remained on top of the screen and the mineral matter, which remained finely dispersed, followed the flow of the water and formed the reject. Both the product and reject material were dried in an oven $\left(110^{\circ} \mathrm{C}\right)$ for 24 hours. The dried samples were then weighed and packaged for storage.

\subsection{Kinetics of Agglomerate Growth}

In the investigations in which the kinetics of agglomerate growth was examined, $500 \mathrm{ml}$ of a 12 wt $\%$ coal slurry was transferred into a glass mixing vessel. This vessel was then placed on a Waring variable speed blender and the coal slurry was dispersed at $22000 \mathrm{rpm}$ for $1 \mathrm{~min}$. The binder, either the emulsion or pure kerosene, was then added in a single dose and mixing was continued for a predetermined period of time. For the pure kerosene, this mixing time was varied between $0 \mathrm{~s}$ and 150 $\mathrm{s}$, and for the emulsion the mixing time was varied between $0 \mathrm{~s}$ and $15 \mathrm{~s}$. The agglomerated slurry was then poured over a series of screens with aperture sizes $150 \mu \mathrm{m}$ and $355 \mu \mathrm{m}$. The solids in each size fraction were dried in an oven $\left(110^{\circ} \mathrm{C}\right)$ for 24 hours. The dried samples were then weighed and packaged for storage.

\subsection{Emulsion Stability}


To examine the stability of the emulsion within the turbulent environment of the agglomeration process, the conductivity of an emulsion-tap water slurry was measured as a function of agitation time. The conductivity of the suspension provided a measure of emulsion stability as a change in conductivity indicated degradation of the emulsion structure and release of the internal salt solution to the surrounding liquid. To simplify the measurements these experiments were carried out in the absence of the coal feed. These experimental conditions were considered sufficient as the aim was to confirm the occurrence of degradation rather than provide a quantitative assessment. In a given experiment, $8 \mathrm{~g}$ of emulsion was dispersed within $500 \mathrm{ml}$ of tap water and agitated using the Waring variable speed blender. The agitation time was varied between $0-60 \mathrm{~s}$ and the conductivity was measured using a Eutech multi-parameter probe. Prior to a conductivity measurement, the globules of emulsion were removed using filter paper. Each measurement was repeated three times.

\section{RESULTS}

\subsection{Influence of Organic Liquid Dosage}

In these experiments the effect of the organic liquid dosage on the product yield was investigated. By comparing the organic liquid dosage required by each binder to achieve a given yield, the reduction in the organic liquid requirement achieved by the emulsion was determined. Figure 4 presents the yield as a function of organic liquid dosage for diesel, kerosene and the emulsion. The yield is defined as the mass of the dry product agglomerates which remained on top of the screen as a percentage of the total dry feed. A product yield of $90 \mathrm{wt} \%$ effectively indicates that complete recovery of the carbonaceous material has been achieved as the ash $\%$ of the feed is $10 \%$. Also, the organic liquid dosage is defined as the mass of organic liquid within the binder as a percentage of the dry coal feed. Consequently, the organic liquid dosage values for the emulsion include the cumulative mass of the kerosene and emulsifier but not the mass of the water.

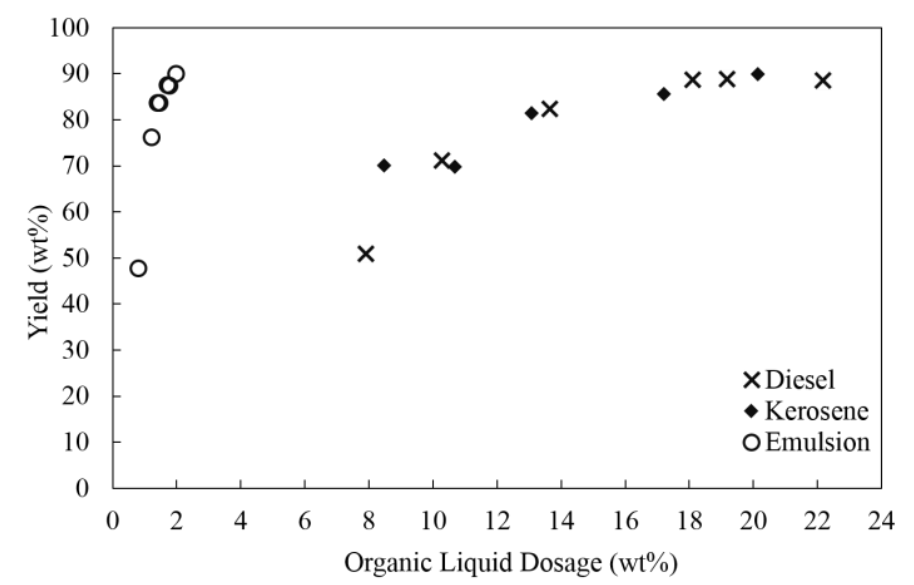

Figure 4. Yield of product coal as a function of organic liquid dosage for pure diesel, pure kerosene and the emulsion.

In Figure 4 it can be seen that the general trend for each of the binders is the same. An increase in the organic liquid dosage results in an increase in the yield of fine coal product. This increase in yield continues up until a certain dosage after which a plateau is observed. This plateau occurs when there is sufficient binder present to completely agglomerate all of the carbonaceous material in the feed. Prior to this plateau there is insufficient binder to form all of the coal particles into large, discrete agglomerates and, as such, some valuable material is lost to the reject.

Now, by comparing the results for each of the binders it can be seen that the results for the pure oils are effectively the same, while the results for the emulsion are considerably different. Considering 
firstly the pure oil binders, i.e. the kerosene and the diesel, the consistency in the result is not surprising as it agrees with the results of Capes and Germain (1982). Their results showed that oils of varying densities and viscosities can achieve comparable yields at a given organic liquid dosage. It should be noted that the result for pure diesel is the same as that presented in the previous work (van Netten et al., 2014). This result, combined with the use of the same coal feed, meant that the results for the emulsion presented in this study are comparable with the results in the previous study. Furthermore, the pure kerosene was investigated in this work to confirm the validity of the comparison between the results for newly formulated emulsion and the pure diesel results. The continuous phase of the newly formulated emulsion was kerosene, whereas for all previous work it was diesel.

Considering now the results for the emulsion, a significant variation can be seen with the results for the pure oils. That is, a substantially reduced amount of organic liquid is required to achieve agglomeration. As aforementioned, complete agglomeration is achieved at the dosages above the point at which the plateau in yield occurs. Therefore, the minimum dosage to achieve complete agglomeration of all of the carbonaceous material in the feed is the dosage from which the plateau commences. For pure oil, the minimum dosage for complete agglomeration of the particles is $17 \mathrm{wt} \%$ whereas for the emulsion an organic liquid dosage of only $1.7 \mathrm{wt} \%$ is required. Therefore, a 10-fold reduction in the organic liquid requirement has been achieved through the use of the emulsion as a binder.

\subsection{Influence of Agitation Time}

During agglomeration experiments the point at which agglomeration is complete is obvious because there is a dramatic change in the colour of the coal slurry. That is, initially the slurry is black in colour due to the finely dispersed coal particles. However, as these particles become agglomerated and effectively removed from suspension, the bulk liquid turns light brown in colour. This colour is representative of the clay which remains finely dispersed in the liquid. Figure 5 presents a) the feed slurry and b) the agglomerated slurry.

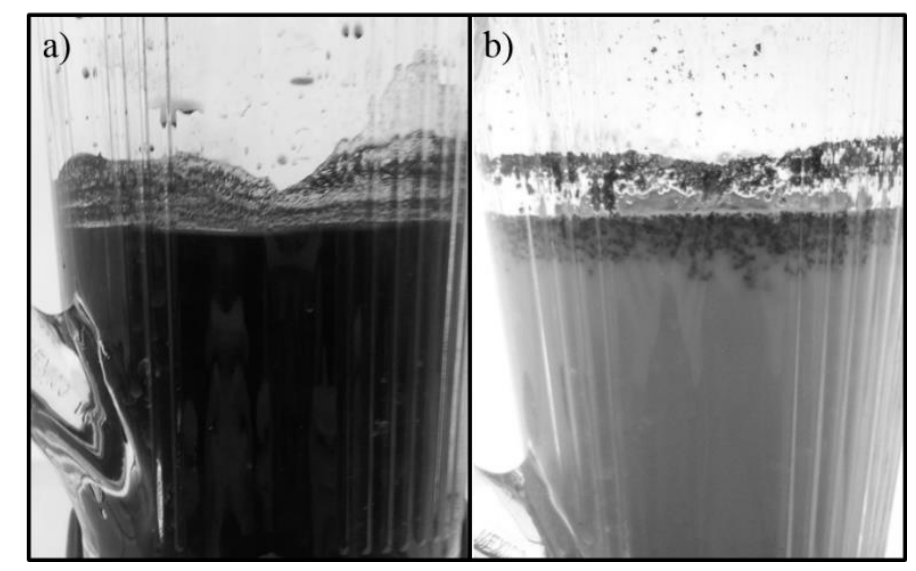

Figure 5. A glass jug containing a) the feed slurry and b) the agglomerated slurry. Note the colour change of the bulk liquid.

Now, due to this distinct change in the appearance of the slurry it is relatively easy to establish the optimum agitation time. Nevertheless, an investigation into the influence of agitation time was deemed necessary. More specifically this work examined the kinetics of agglomerate growth for the emulsion and pure kerosene. This work was considered essential as a result of the substantial variation in the agitation time required to achieve agglomeration for the two types of binders. That is, pure oils required $120 \mathrm{~s}$ while the emulsion required only $7 \mathrm{~s}$. It should be noted that the agitation time required 
for the newly formulated emulsion tested in this work was also less than that required by the emulsion formulations tested in previous work (van Netten et al., 2014).

Therefore, an investigation was carried out to examine the kinetics of agglomerate growth for the emulsion and elucidate the differences between the emulsion and pure oil. As described in the Experimental Method section, the experiments were carried out using agitation times between 0 - 150 $\mathrm{s}$ for the pure kerosene and between $0-15 \mathrm{~s}$ for the emulsion. Then in each case the agglomerated slurry was poured over a series of screens with aperture sizes of $150 \mu \mathrm{m}$ and $355 \mu \mathrm{m}$. By measuring the mass fraction of particles within each size range as a function of time the growth of agglomerates could be monitored. It should be noted that the measurement taken at time $=0 \mathrm{~s}$ was in the absence of binder and thus was representative of the feed material.

Figure 6 presents the results from these experiments and shows the yield in each size range as a function of time. The size ranges are $-150 \mu \mathrm{m}$ (less than $150 \mu \mathrm{m}$ ), $+150-355 \mu \mathrm{m}$ (greater than $150 \mu \mathrm{m}$ and less than $350 \mu \mathrm{m}$ ) and $+355 \mu \mathrm{m}$ (greater than $355 \mu \mathrm{m}$ ). It should be noted that in each case sufficient binder was available such that complete agglomeration of the particles would occur if time permitted. Therefore an organic liquid dosage of $1.7 \mathrm{wt} \%$ was used for the emulsion and for the pure kerosene a dosage of $17 \mathrm{wt} \%$ was used. These dosages were selected as a result of the findings in Figure 4 and represent the minimum dosages required to achieve agglomeration. Also, note the order of magnitude difference in the time scales of the two binders.
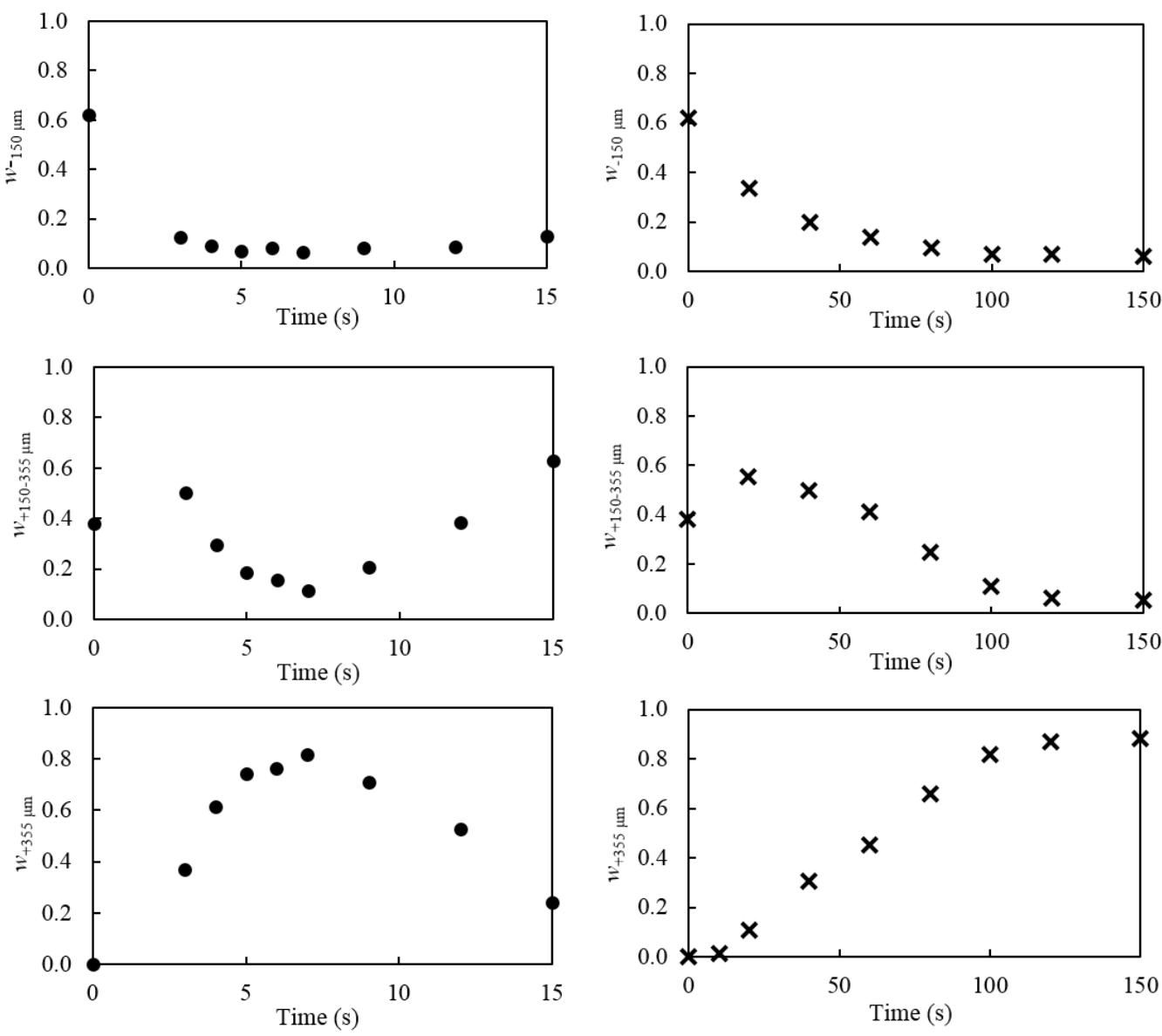

Figure 6. Influence of agitation on yield of product coal for the emulsion binder ( $)$ and a pure kerosene binder ( $\boldsymbol{x}$ ). The yield is presented in size fractions of $-150 \mu \mathrm{m},+150-355 \mu \mathrm{m}$ and $+355 \mu \mathrm{m}$. The organic liquid dosages for the emulsion and pure kerosene were $1.7 \mathrm{wt} \%$ and $17 \mathrm{wt} \%$, respectively. Note the order of magnitude difference in the time scales of the two binders. 
Considering firstly the results for the $-150 \mu \mathrm{m}$ size fraction, it can be seen that, while they are on different time scales, the general trend for the two binders is effectively the same. There is a decrease in the mass fraction of particles which are $-150 \mu \mathrm{m}$ from 0.6 at $0 \mathrm{~s}$ to 0.1 at $5 \mathrm{~s}$ for the emulsion and $60 \mathrm{~s}$ for pure kerosene. This decrease is followed by a plateau which indicates that all of the carbonaceous material has been formed into larger agglomerates and the only remaining material in the $-150 \mu \mathrm{m}$ size fraction is the unaffected mineral matter.

In the $+150-355 \mu \mathrm{m}$ size range the general trend for the two binders is initially the same. There is a slight increase in the mass fraction of $+150-355 \mu \mathrm{m}$ agglomerates followed by a decrease in the mass of agglomerates within this size range. Of course, once again, the results for the two binders are on drastically different time scales with the decrease occurring after $3 \mathrm{~s}$ for the emulsion and after 40 $\mathrm{s}$ for pure kerosene. This decrease continues with time as the agglomerates continue to grow and move into the $+355 \mu \mathrm{m}$ size range. After $7 \mathrm{~s}$ for the emulsion and $120 \mathrm{~s}$ for the pure kerosene there are effectively no particles left in the $+150-355 \mu \mathrm{m}$ size range indicating that they have all grown into larger agglomerates. Interestingly, an increase in the mass of agglomerates within the $+150-355 \mu \mathrm{m}$ begins after $9 \mathrm{~s}$ for the emulsion; a trend which is not observed for the pure kerosene. This increase indicates that the agglomerates made with the emulsion binder are being reduced in size with extended agitation such that they fall back into the intermediate size range.

As similar to the results for the $+150-355 \mu \mathrm{m}$ size range, the general trend is initially the same for both binders in the $+355 \mu \mathrm{m}$ size range. There is a small period of minimal growth followed by a rapid increase in the mass fraction of $+355 \mu \mathrm{m}$ agglomerates. This rapid increase culminates at a maximum value which is indicative of the carbonaceous, i.e. recoverable material, content of the feed. The emulsion reaches this maximum value, and thus complete agglomeration of the coal particles within $7 \mathrm{~s}$. However the pure kerosene requires $120 \mathrm{~s}$ to reach this point. Then, following the attainment of this maximum the results for the two binders are dissimilar. The results for the emulsion binder exhibit a decrease in yield indicating that the agglomerates are reduced in size such that they fall back into the intermediate size range. Whereas the results for the pure kerosene exhibit a plateau in the mass fraction of $+355 \mu \mathrm{m}$ at extended agitation times.

\subsection{Emulsion Stability}

Due to the presence of sodium chloride within the dispersed phase of the emulsion the breakdown of the emulsion could be studied readily via changes in the conductivity of the suspending liquid. That is, if the emulsion structure was breaking down as suspected, the dissolved salt would be released and influence the conductivity of the suspending liquid. In these experiments emulsion was dispersed in tap water using the Waring blender and the conductivity of the suspension was measured as a function of agitation time. Figure 7 presents the conductivity of the suspending liquid as a function of agitation time. Also presented in the figure is the maximum limit of the conductivity which would result if all of the salt within the internal aqueous phase of the emulsion was released to the suspending liquid. It should be noted that the experimental curve begins at zero as each conductivity reading was calibrated to account for the conductivity of the tap water. 


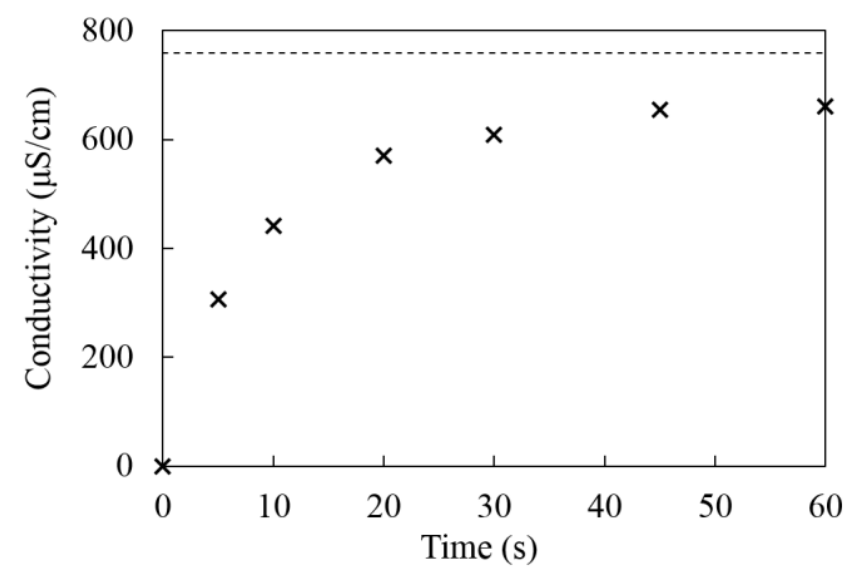

Figure 7. Conductivity of the suspending liquid as a function of agitation time.

The results in Figure 7 indicate that the conductivity of the suspending liquid increases as a function of agitation time. This increase is initially quite rapid, with the conductivity rising to approximately $600 \mu \mathrm{S} / \mathrm{cm}$ within $20 \mathrm{~s}$, which is $75 \%$ of the maximum level if all of the salt within the emulsion was released. After this time, however the conductivity of the suspension tapers off to a constant level. Therefore, it appears that the emulsion does experience degradation within the turbulent, aqueous environment of the agglomeration process. Moreover, it appears that the time scale of the breakdown is similar in magnitude to the time scale of the agglomeration process.

\section{DISCUSSION}

\subsection{Organic Liquid Dosage Reduction}

The 10-fold reduction achieved with the newly formulated binder is a significant improvement on the 7.5-fold reduction achieved in the previous work. Therefore, the new results indicate that kerosene is more suitable for use as the continuous phase of the emulsion than diesel. Moreover, as it was shown that diesel and kerosene possess the same agglomerating characteristics when used in their pure form, these results indicate that the use of kerosene leads to a more suitable emulsion for use in the agglomeration process.

It has been considered that the increased suitability of the newly formulated emulsion relates to a change in the viscosity of the continuous phase. That is, kerosene has a viscosity of $0.0016 \mathrm{~Pa}$ s while diesel has a viscosity of $0.0025 \mathrm{~Pa} \mathrm{~s}$. A reduction in the viscosity of the continuous phase is consequential because continuous phase viscosity affects the overall rheology of the emulsion. More specifically it affects the internal droplet size and the viscosity of the emulsion; both of which are factors which may affect the stability and behaviour of the emulsion within the turbulent, aqueous environment of the agglomeration process. At this stage, however, a detailed investigation into the rheological properties of the emulsion has not been carried out. A study of this nature would be beneficial in the future to relate the performance of the emulsion as a binder with its rheological properties.

\subsection{Kinetics of Agglomerate Growth}

The results from the experiments which considered the influence of agitation time highlighted some similarities and some differences between the agglomeration kinetics of the two binders. The most striking difference between the two sets of results was the substantial variation in the time required to achieve agglomeration. That is, the emulsion required only $7 \mathrm{~s}$ to completely agglomerate all of the carbonaceous material in the feed whereas the pure kerosene required $120 \mathrm{~s}$. This difference, 
therefore, means that the use of the emulsion as the binder has resulted in an agglomeration process which is 17 times faster than the conventional process using pure oil. To account for this dramatic increase in the speed of agglomeration when using the emulsion attention has once again been drawn to binder viscosity. Pure kerosene has a viscosity of $0.0016 \mathrm{~Pa} \mathrm{~s}$ whereas the viscosity of a HIP emulsion, depending on composition, is around $100 \mathrm{~Pa}$ s (Galvin et al., 2001). Now, such a significant variation in binder viscosity could produce the observed variation in the agglomeration kinetics by modifying the solid-binder collision efficiency. That is, a high viscosity binder may collide and stick to solid particles with a higher efficiency than a low viscosity binder. Further work is required to confirm this proposal.

Moving past the difference in the required agglomeration time for the two binders, a comparison of the underlying behaviour of the growth of agglomerates shows further differences. To illustrate these differences, along with the similarities in the agglomerate growth behaviour, Figure 8 presents the time normalised kinetics of agglomerate growth for the two binders. Once again the results are presented for the size fractions: $-150 \mu \mathrm{m},+150-355 \mu \mathrm{m}$ and $+355 \mu \mathrm{m}$. The agitation times were normalised around the time required to achieve agglomeration. Therefore the agitation times for the emulsion were normalised around $7 \mathrm{~s}$ and were normalised around $120 \mathrm{~s}$ for the pure kerosene.
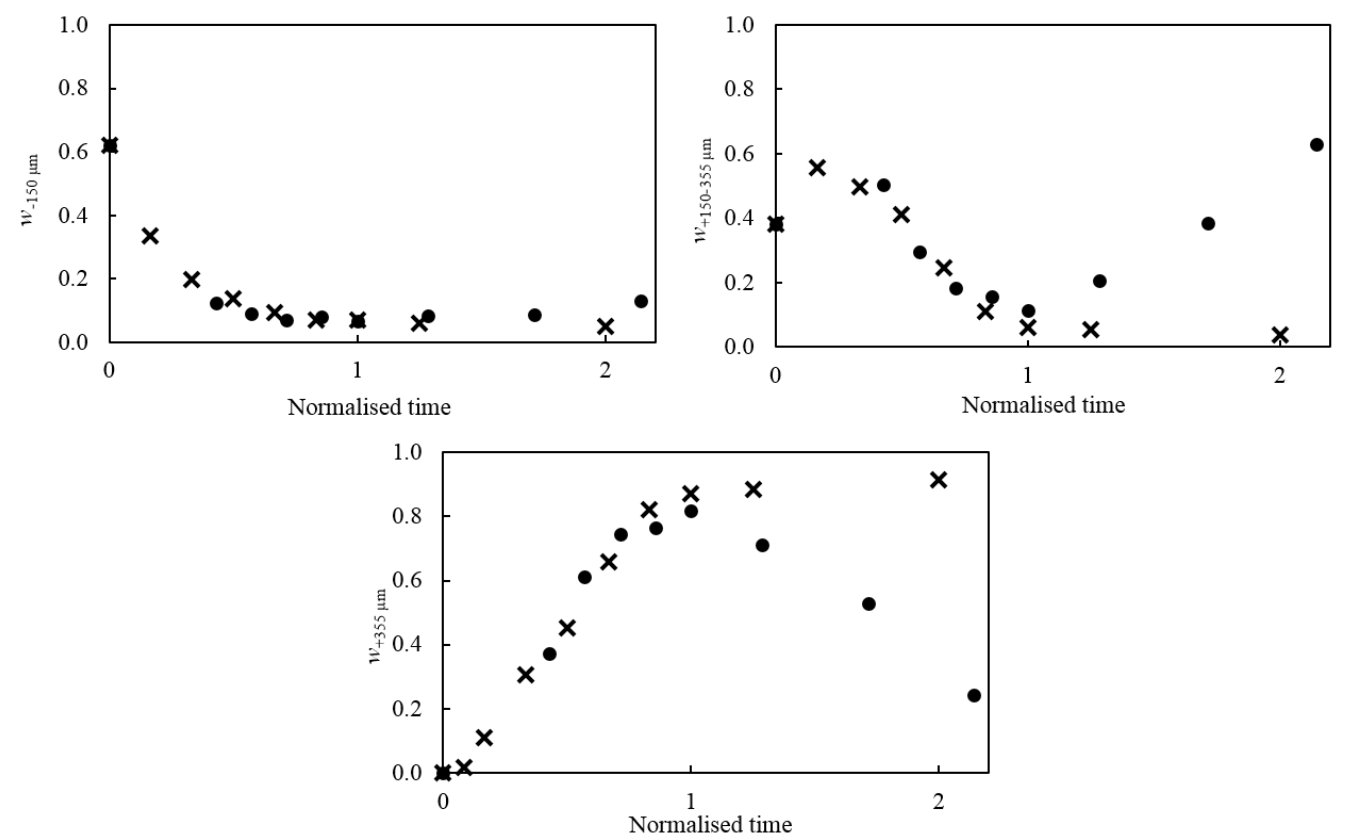

Figure 8. Time normalised kinetics of agglomerate growth for the emulsion binder $(\mathbf{)})$ and a pure kerosene binder ( $\mathbf{x}$ ).

In general, the results in Figure 8 indicate similar behaviour for the pure kerosene and the emulsion prior to the time required to reach agglomeration, i.e. a normalised time of 1 . However, after this time clear differences can be observed, especially in the $+150-355 \mu \mathrm{m}$ and the $+355 \mu \mathrm{m}$ size ranges. In the case of the emulsion, the results in these size ranges indicate that the agglomerates are being reduced in size and this reduction continues with extended agitation times. The reduction in agglomerate size is so significant that the majority of the agglomerates made from the emulsion are less than $355 \mu \mathrm{m}$ in size by the end of the time period studied (which was $15 \mathrm{~s}$ ).

It may be suggested that the reduction in agglomerate size which occurs when using the emulsion is the result of agglomerate breakage. However, in the presence of sufficient binder, this breakage and destruction would presumably be matched by re-agglomeration. Moreover, if this was the case the results should reflect the attainment of a steady state, as similar to that exhibited by the results for the pure kerosene. As a steady state was not reached in the results for the emulsion it may be 
concluded that at extended agitation times the emulsion itself is being broken down or degraded. Break down of the emulsion would result in a decrease in agglomerate size as there would no longer be sufficient binder available to maintain the structural integrity of the agglomerates. The results presented in Figure 7 also support this conclusion as substantial emulsion degradation was shown to occur over a similar time scale. Of course, the results in Figure 7 only apply in a qualitative sense as solid particles also interact with the emulsion binder in an agglomeration process, however the findings still highlight the importance of understanding the role of emulsion degradation and the significant implications it has for optimisation of the agglomeration process.

\subsection{Minimisation of Agglomeration time}

The ability of the emulsion to agglomerate coal in $7 \mathrm{~s}$ was an impressive achievement and it instigated a desire to establish the minimum agglomeration time possible. A minimised processing time is desirable as it results in reduced capital costs, through reduced unit sizes, and increased unit throughput capacities. Therefore, in an attempt to further reduce the processing time the emulsion was pre-dispersed prior to its introduction into the slurry of coal and mineral particles. It was considered that this method would further reduce the agglomeration time required as the combination of two evenly dispersed suspensions would facilitate fast contacting and agglomeration. It was found that if the emulsion was dispersed for $4 \mathrm{~s}$ prior to the introduction of the slurry, the agitation time required to achieve complete agglomeration of the carbonaceous material was only $3 \mathrm{~s}$. At these conditions and an organic liquid dosage of $1.7 \mathrm{wt} \%$ a yield of $88 \mathrm{wt} \%$ was achieved; a result which is comparable to the results presented in Figure 4.

\section{CONCLUSION}

In this work a high internal phase emulsion was used for the selective agglomeration of fine coal. The emulsion was composed of 2.5 vol\% kerosene, 2.5 vol\% sorbitan mono-oleate and 95 vol\% aqueous $\mathrm{NaCl}$ solution. Agglomeration experiments were carried out using the emulsion. Separate experiments were also carried out using pure kerosene and pure diesel to serve as a comparison. It was found that the use of the emulsion led to a 10-fold decrease in the organic liquid dosage required to achieve agglomeration as compared to experiments in which pure oil was used.

An investigation was also carried out to examine the influence of agitation time on the agglomeration process using the emulsion binder. Once again, experiments were also carried out using pure kerosene to serve as a comparison. It was found that agglomeration time required when using the emulsion was $7 \mathrm{~s}$ whereas the time required for the pure kerosene was $120 \mathrm{~s}$. The high viscosity of the emulsion was attributed to the considerable increase in the speed with which the particles were agglomerated.

Despite the order of magnitude difference in the agglomeration time, the general agglomeration behaviour of the two binders was, initially, similar. However, after the point at which complete agglomeration was reached there was a deviation in the agglomeration behaviour of the two binders. The emulsion binder appeared to breakdown and thus a reduction in the size of agglomerates was observed whereas the size of the agglomerates remained constant with extended mixing times using pure kerosene.

This work has shown that a high internal phase water-in-oil emulsion can agglomerate fine coal 17-times faster and with 10-times less organic liquid than when using pure oil.

\section{ACKNOWLEDGEMENTS}


The financial support from the Australian Coal Association Research Program and the Australian Research Council for this work is greatly appreciated.

\section{REFERENCES}

Z. Aktas, Some factors affecting spherical oil agglomeration performace of coal fines, International Journal of Mineral Processing, 65 (2002) 177-190.

C.N. Bensley, A.R. Swanson, S.K. Nicol, The effect of emulsification on the selective agglomeration of fine coal, International Journal of Mineral Processing, 4 (1977) 173-184

A.H. Brisse, W.L. McMorris, Coal - Convertol Process, in: AIME Transactions, 1959, pp. 4.

N.R. Cameron, High internal phase emulsion templating as a route to well-defined porous polymers Polymer, 46 (2005) 1439-1449.

C.E. Capes, K. Darcovich, A Survey of Oil Agglomeration in Wet Fine Coal Processing, Powder Technology, 40 (1984) 43 - 52.

C.E. Capes, R.J. Germain, Selective Oil Agglomeration in Fine Coal Beneficiation, in: Y.A. Liu (Ed.) Physical Cleaning of Coal - Present and Developing Methods, Marcel Dekker, Inc, New York, 1982.

K. Darcovich, C.E. Capes, F.D.F. Talbot, Surface Characteristics of Coal-Oil Agglomerates in the Floc Regime, Energy \& Fuels 3(1988) 64 - 70.

Diesel; MSDS [Online]; ExxonMobil, 2009. www.petrogas.com.au/Files/Mobil/ULSD.pdf (accessed August 27, 2014)

K. P. Galvin, S. M. Iveson, Cleaning of coarse and small coal, in D. Osbourne (Ed.) The Coal Handbook: Towards Cleaner Production Woodhead Publishing, Oxford, 2013.

K.P. Galvin, S.J. Pratten, N.G. Shankar, G.M. Evans, S.R. Biggs, D. Tunaley, Production of high internal phase emulsions using rising air bubbles, Chemical Engineering Science, 56 (2001) 6285-6293.

A.B. Garcia, J.M.G. Vega, M.R. Martinez-Tarazona, Effects ot oil concentration and particle size on the cleaning of Spanish high-rank coals by agglomeration with n-heptane, Fuel, 74 (1995) 1692-1697.

R.Q. Honaker, J. Kohmuench, G.H. Luttrell, Cleaning of fine and ultrafine coal, in: D. Osbourne (Ed.) The Coal Handbook: Towards Cleaner Production Woodhead Publishing, Oxford, 2013.

V.P. Mehrotra, K.V.S. Sastry, B.W. Morey, Review of Oil Agglomeration Techniques For Processing of Fine Coals, International Journal of Mineral Processing, 11 (1983) 175-201.

T. Miettinen, J. Ralston, D. Fornasiero, The limits of fine particle flotation, Minerals Engineering, 23 (2010) 420-437.

Kerosene; MSDS [Online]; Recochem Inc, December 22, 2011.

http://www.recochem.com.au/files/downloads/Kerosene_Blue_Nov11.pdf (accessed Feb 06, 2015)

Sorbitan Mono-oleate, MSDS [Online]; Sigma-Aldrich, May 17, 2013.

http://www.sigmaaldrich.com/australia.html (accessed Feb 06, 2015)

S.M. Shrauti, D.W. Arnold, Recovery of waste fine coal by oil agglomeration, Fuel, 74 (1994) 459-465.

W.G. Steedman, S.V. Krishnan, Oil Agglomeration Process for the Treatment of Fine Coal, in: S.K. Mishra, R.R. Klimpel (Eds.) Fine Coal Processing, Noyes Publications, New Jersey, 1987. 
A.R. Swanson, S.K. Nicol, C.N. Bensley, Selective Agglomeration: A solution to Problems in the Efficient Treatment of Fine Coal, in: Chemeca 77, Canberra, 1977.

K. van Netten, R. Moreno-Atanasio, K.P. Galvin, Fine Particle Beneficiation through Selective Agglomeration with an Emulsion Binder, Industrial and Engineering Chemical Research, 53 (2014) 1574715754 .

K. van Netten, R. Moreno-Atanasio, K. P. Galvin, A kinetic study of a modified fine coal agglomeration process. Procedia Engineering 102, (2015) 508-516 